\title{
Bacterial Adherence to Guided Tissue Regeneration Barrier Membranes Exposed to the Oral Environment
}

\author{
Yen-Ting Chen, * Hom-Lay Wang, ${ }^{\dagger}$ Dennis E. Lopatin, ${ }^{\ddagger}$ Robert O’Neal, ${ }^{\S}$ and \\ R. Lamont MacNeil ${ }^{\dagger}$
}

\begin{abstract}
MICROBIAL COLONIZATION OF BARRIER MATERIALS used in guided tissue regeneration (GTR) is known to adversely affect treatment outcomes. The purpose of this study was to compare the rate at which 11 commonly-occurring oral bacteria species colonize three different barrier materials (collagen, expanded polytetrafluoroethylene, and polylactic acid). The study group consisted of 10 systemically healthy individuals with no history of periodontal disease and absence of antimicrobial therapy within the previous 3 months. In each patient, 4 teeth per quadrant (P1, P2, M1, M2) were selected and 3 teeth were randomly assigned as test teeth while the remaining tooth acted as a control site (i.e., natural colonization of the tooth surface). These teeth were then randomly assigned to receive one of the three barrier types (i.e., each patient received 4 barriers of each type, 1 per quadrant). A $2 \times 5 \mathrm{~mm}$ piece of barrier material was positioned over the oral surface of the buccal marginal gingiva and secured with an external sling suture. With oral hygiene procedures suspended, one barrier of each type was collected at $1,3,7$, and 14 days. Slot immunoblot assay demonstrated that all species types (A. actinomycetemcomitans, $A$. viscosus, B. melaninogenicus, $F$. nucleatum, $P$. gingivalis, $P$. intermedia, $S$. mutans, $S$. sanguis, Selenomonas sputigena, $T$. denticola, and $T$. vincentii) were present. Semi-quantitative scoring (scale 0 to 3 ) of slot blot results and analysis by chi-square ratio and Pearson correlation test indicated that while total bacteria adherence increased over time $(P<0.05)$, the 3 barrier types and the control sites did not differ in numbers or species of colonizing bacteria detected per time point. These results suggest that under these experimental conditions the barrier materials tested do not differ in bacteria adherence or antimicrobial properties. J Periodontol 1997;68:172-179.
\end{abstract}

Key Words: Membranes, artificial/microbiology; membranes, barrier/microbiology; guided tissue regeneration; collagen; polylactic acid; polytetrafluoroethylene.

Studies have demonstrated that favorable results can be achieved utilizing GTR principles and techniques. ${ }^{1-3}$ Long-term studies using GTR therapy have shown that probing depth reduction and clinical attachment level gain can be obtained and maintained up to 5 years. ${ }^{3}$ Similarly, encouraging results have also been shown in combining GTR procedures with dental implant therapy. ${ }^{4.5}$ However,

\footnotetext{
*Currently, Private Practice, Taipei, Taiwan; previously, Department of Periodontics/Prevention/Geriatrics, School of Dentistry, University of Michigan, Ann Arbor, MI.

Department of Periodontics/Prevention/Geriatrics, School of Dentistry, University of Michigan, Ann Arbor, MI.

${ }^{\prime}$ Department of Biologic and Material Sciences.

sCurrently, Department of Periodontics, School of Dentistry, University of Washington, Seattle, WA; previously, University of Michigan.
}

less favorable outcomes occur when acute infections develop requiring early removal of membranes; ${ }^{4.5}$ in these cases, osseous defects heal with granulation tissue instead of bone. ${ }^{5}$ Hence, postsurgical colonization and infection of GTR barriers may be a major limiting factor in achieving successful clinical regeneration. ${ }^{6}$

Clinically, attempts have been made to prevent exposure of barrier materials to the oral environment. However, due to a number of problems including unfavorable dental morphology, ${ }^{7}$ flap dehiscence, ${ }^{4}$ gingival recession, ${ }^{8}$ or incomplete flap closure, ${ }^{9}$ membrane exposure is a common sequela during the early healing phase. Exposure may permit a communication between the oral environment and newly forming tissues which may increase the potential for infection of the barrier. ${ }^{8}$ Studies have dem- 
onstrated that microbes indigenous to the oral cavity frequently colonize GTR membranes ${ }^{10}$ and that this bacteria adherence adversely influences the final clinical result."

Currently, limited data are available on either the qualitative or quantitative characteristics of the microbiota that adhere to exposed membranes. ${ }^{10}$ In an in vitro study conducted by Wang et al., ${ }^{12}$ the adherence of oral microorganisms to three different GTR barriers-collagen," expanded polytetrafluoroethylene (ePTFE) ${ }^{\mathrm{I}}$ and polyglactin $910^{\#}$ - was analyzed. Results indicated that certain species [i.e., Actinomyces viscosus (Av), Actinobacillus actinomycetemcomitans (Aa), Porphyromonas gingivalis ( $P g)$, Streptococcus mutans (Sm), Fusobacterium nucleatum $(\mathrm{Fn})$, and Selenomonas sputigena (Sel)] display relatively strong adherence to all membrane types. Among them, $\mathrm{Sm}$ has been reported as a pioneer species in the aggregation of dental plaque, ${ }^{13}$ while $\mathrm{Av}, \mathrm{Aa}, \mathrm{Pg}, \mathrm{Fn}$ and $\mathrm{Sel}$ are species associated with destructive periodontal disease. ${ }^{14-17}$ Adherence of these organisms to GTR membranes may facilitate the recurrence of periodontitis and supporting alveolar bone loss. Therefore, the purpose of this study was to examine the ability of 11 commonlyoccurring oral bacteria to adhere to 3 different GTR membranes (collagen, ePTFE, and polylactic acid**) in vivo.

\section{MATERIALS AND METHODS}

\section{Membrane Selection}

Three different GTR membranes were selected for this study: collagen, ePTFE, and polylactic acid blended with citric acid ester (PLA). Collagen and PLA are absorbable in the bio-environment, whereas ePTFE is nonabsorbable and bio-inert.

\section{Microorganism Selection and Preparation}

Eleven different commonly-occurring oral bacteria species were assessed including: $A a$ serotype b (ATCC: the American Type Culture Collection 43718), Av (ATCC 15987), Bacteroides melaninogenicus (Bm), Fn, Prevotella intermedia (Pi), Pg, Sel, Sm (ATCC 25175), Streptococcus sanguis (Ss), Treponema denticola (ATCC 35405) (Td), and Treponema vincentii (ATCC 35580) $(T v)$. Strains other than those obtained from the ATCC were cultured from patients with adult periodontitis. Following cultivation, all bacteria were harvested, washed, lyophilized, and stored at $-20^{\circ} \mathrm{C}$ before further use.

\section{Patient Entry Criteria}

A total of 10 healthy subjects, 6 male and 4 female, aged 29 to 33 years (average age $=31$ ) participated in this

BioMend, Calcitek Inc., Carlsbad, CA.

'Gore-Tex, W.L. Gore and Associates, Inc., Flagstaff, AZ.

"Vicryl, Ethicon, Inc., East Brunswick, NJ.

**Guidor, Guidor USA, Bensenville, IL.

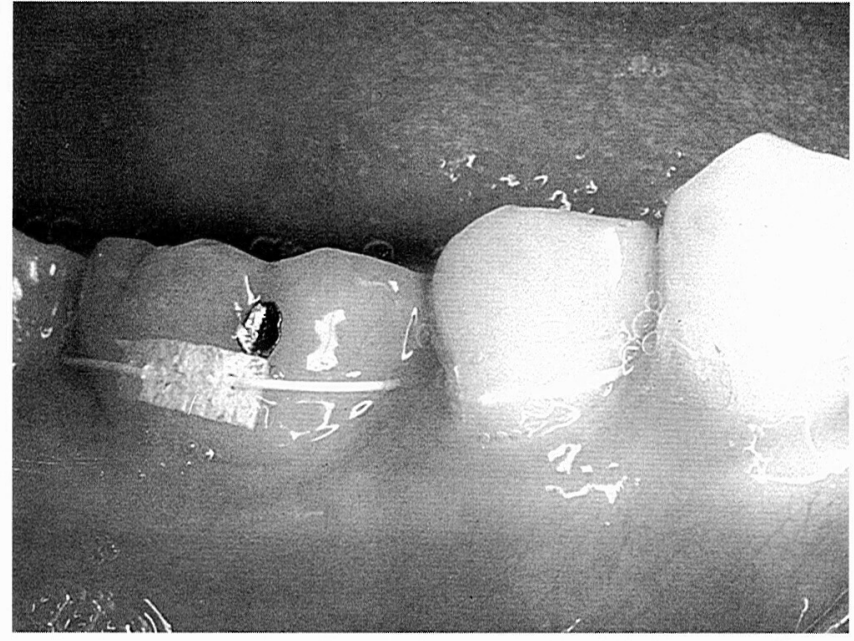

Figure 1. Membranes were secured over the oral surface of the buccal gingival margin with an external suture. Membranes placed from $P I$ to $M 1$ were PLA, collagen, and PPTFE. M2 was used as control site. Absorbable membrane expansion was noted in this day I specimen.

study. All subjects were either dental graduate students or staff members at the University of Michigan. None of the participants had received antibiotic therapy within the last 3 months. All subjects were assessed as periodontally stable and healthy with probing depth $<4 \mathrm{~mm}$. Oral hygiene procedures (including toothbrushing, flossing and use of mouthrinse) were suspended during the experimental period. The study protocol was approved by the University of Michigan and all participants signed an informed consent form.

\section{Experimental Design and Specimen Preparation}

All individuals received an oral prophylaxis one day prior to membrane placement. Membranes were precisely cut into $2 \times 5 \mathrm{~mm}$ rectangular units. Four teeth of each quadrant (1st, 2nd premolars, and molars) were randomly assigned as the 3 test sites (with one of each type of membrane) and one control site (i.e., natural colonization of the tooth). Each quadrant was then randomly assigned to one of the 4 experimental time periods: $1,3,7$, or 14 days. Thus each subject had 12 membranes placed. Membranes were placed supragingivally to lie over the oral surface of the buccal gingiva. These supragingival membranes were then stabilized by placing an external sling suture through the corners of the membrane and around the lingual surface of the test tooth (Fig. 1).

For each participant at each timepoint, $(1,3,7$, and 14 days), all membranes in a single quadrant were retrieved; supragingival plaque from the buccal aspect of the control site in that quadrant was collected using Gracey \#11/12 curets. Control plaque samples and the retrieved membranes were placed in cryotubes $^{\text {t+ }}$ containing $0.5 \mathrm{ml}$ PBS

Vangard, Neptune, NJ. 
Table 1. Distribution of Bacterial Adherence Scores

\begin{tabular}{|c|c|c|c|c|c|c|c|c|c|c|c|}
\hline $\begin{array}{l}\text { Score } \\
(\%)\end{array}$ & $\mathrm{Aa}$ & Av & $\mathrm{Bm}$ & Fn & $\mathrm{Pg}$ & $\mathrm{Pi}$ & $\mathrm{Sm}$ & Ss & Sel & $\mathrm{Td}$ & $\mathrm{Tv}$ \\
\hline $\begin{array}{l}0 \text { and } 1 \\
2 \text { and } 3\end{array}$ & $\begin{array}{c}73 \\
(57) \\
55 \\
(43)\end{array}$ & $\begin{array}{c}56 \\
(44) \\
72 \\
(56)\end{array}$ & $\begin{array}{c}96 \\
(75) \\
32 \\
(25)\end{array}$ & $\begin{array}{c}92 \\
(72) \\
36 \\
(28)\end{array}$ & $\begin{array}{c}101 \\
(79) \\
27 \\
(21)\end{array}$ & $\begin{array}{c}102 \\
(80) \\
26 \\
(20)\end{array}$ & $\begin{array}{l}107 \\
(84) \\
21 \\
(16)\end{array}$ & $\begin{array}{c}98 \\
(77) \\
30 \\
(23)\end{array}$ & $\begin{array}{c}121 \\
(98) \\
7 \\
(2)\end{array}$ & $\begin{array}{c}111 \\
(87) \\
17 \\
(13)\end{array}$ & $\begin{array}{c}113 \\
(88) \\
15 \\
(12)\end{array}$ \\
\hline $\begin{array}{l}0=\text { no } \\
1=\text { fain } \\
2=\text { subs } \\
3=\text { stro } \\
0 \text { and } 1 \\
2 \text { and } 3\end{array}$ & $\begin{array}{l}\text { olor d } \\
\text { t color } \\
\text { tantial } \\
\text { ing colo } \\
\text { represe } \\
\text { ceprese }\end{array}$ & $\begin{array}{l}\text { velor } \\
\text { lor p } \\
\text { level } \\
\text { d no } \\
\text { d sul }\end{array}$ & $\begin{array}{l}\text { int. } \\
\text { ent. } \\
\text { nent. } \\
\text { or trac } \\
\text { ntial a }\end{array}$ & & & du & & & & & \\
\hline
\end{tabular}

(phosphate-buffered saline, $0.05 \mathrm{M}$ sodium phosphate, $0.15 \mathrm{M} \mathrm{NaCl}$ [pH 7.4]) and a protease inhibitor cocktail (0.5\% formaldehyde, EDTA $2 \mathrm{mM}$, phenylmethylsulfonyl fluoride $1.0 \mathrm{mM}$, pepstatin A $0.1 \mathrm{mM}$, and leupeptin 0.5 $\mathrm{mg} / \mathrm{liter}$ ). All samples -were stored at $4^{\circ} \mathrm{C}$ prior to performing the slot immunoblot assay (SIB).

\section{Slot Immunoblot Assay (SIB)}

The SIB was performed as originally described by Van Poperin and Lopatin. ${ }^{18}$ Briefly, nitrocellulose membranes $^{\ddagger \neq}$ were soaked in TBS $(0.05 \mathrm{M} \mathrm{NaCl}, 10.0 \mathrm{mM}$ Tris [pH 7.4]) for 30 minutes prior to insertion into a slot blot manifold II. ${ }^{\ddagger}$ Specimens were sonicated ${ }^{\S}$ to disrupt aggregates of plaque particle and $10 \mu l$ specimens were applied to wells of the manifold. The nitrocellulose membranes were then blocked at room temperature for $60 \mathrm{~min}$ utes in a solution of TBS containing $0.5 \%$ non-fat dried milk. ${ }^{19}$ The antibacterial antibodies $(1: 1000)$ which had been previously absorbed with a panel of unrelated bacterial species were then applied to the membrane and allowed to incubate for 1 hour at room temperature. Following 3 washes with TBS-Tween ( 5 minutes each), the nitrocellulose membranes were incubated for 1 hour at room temperature with goat anti-rabbit Ig-G conjugated in alkaline phosphatase ${ }^{\text {III }}(1: 1000)$. Two washes with TBSTween and a final wash with TBS solution were performed (5 minutes for each wash) prior to applying the BCIP-NBT substrate solution. Following maximum color development, the nitrocellulose membranes were washed with distilled water and dried.

Scoring was performed visually against graded concentrations of pure microorganisms homologous to the specific antibody used. Total mass of the specimen was estimated by its reaction with concanavalin A. ${ }^{18}$ The following scoring system (and the approximate level of bacteria detected) was employed for the purpose of qualitative description: $0=$ no color development $\left(<5 \times 10^{4}\right) ; 1=$

\footnotetext{
${ }^{\ddagger}$ Schleicher \& Schuell, Keene, NH.

\$Vortex, Springfield, MA.

I"'Bio-Rad Laboratories, Hercules, CA.

ఇKirkéGaard \& Perry Laboratories, Gaithersburg, MD.
}

faint color development (approximately $5 \times 10^{4}$ ); $2=$ substantial color present (approximately $1 \times 10^{5}$ ); and 3 $=$ maximal color development $\left(>5 \times 10^{5}\right)$. When employing a dichotomous variable, scores of 0 and 1 were considered negative while scores 2 and 3 were considered positive.

\section{Statistical Analysis}

Data regarding membrane collection and bacterial adherence were analyzed statistically. Likelihood ratio chisquare test was used to assess the effects of membrane types on bacterial adherence. Pearson correlation analysis was used to assess the association among tested bacterial species. The alpha level was set at 0.05 .

\section{RESULTS}

A total of one hundred and twenty-eight (128) plaque specimens were collected. At day 1, all membranes and control site specimens originally placed were retrieved as scheduled. By day 3, however, four membranes were "lost" (i.e., absent from the experimental site); including one ePTFE and three PLA membranes. By day 7, one ePTFE, two PLA, and seven collagen membranes were lost. By day 14, one ePTFE, six PLA, and 10 collagen membranes were not retrievable. One patient at day 14 lost all test membranes; therefore no plaque samples (including control site) were collected. Statistical analysis using likelihood ratio chi-square revealed that membrane loss increased significantly with increasing exposure time $(P<0.05)$. The number of membranes lost at day 7 and 14 was significantly greater than that at day 1 , whereas the number of lost membranes at day 3 was only marginally greater than that at day $1(P=0.063)$. Comparison among various membrane types indicated that the loss frequencies of bioabsorbable membranes (collagen and PLA) were significantly higher than that of nonabsorbable membranes (ePTFE) $(P<0.05)$; however, no significant difference was found between collagen and PLA membranes. Membrane expansion was also noted in all bioabsorbable membrane (collagen and PLA) specimens at different time periods.

The results of bacterial adherence at each time point 
were analyzed for treatment effect. No unique bacterial adherence pattern was noted, although bacterial adherence to the collagen membrane was greater than to other test membranes (ePTFE and PLA) and control tooth surfaces (except $P$. intermedia). However, when analyzed with likelihood ratio chi-square test, this difference was not statistically significant.

Table 1 presents the distribution of slot immunoblot assay (SIB) scores. Among the 11 test bacterial species, most of the specimens had negative or only trace amounts (scores 0 or 1) of bacterial adherence with the exception of A. actinomycetemcomitans and A. viscosus. Forty-three percent $(43 \%)$ of specimens had substantial amounts of A. actinomycetemcomitans adherence and $56 \%$ of specimens showed substantial amounts of $A$. viscosus adherence (scores 2 or 3). Ninety-eight percent $(98 \%)$ of specimens had negative or only trace amounts of $S$. sputigena adherence. Data analyzed using Pearson correlation test indicated statistically significant positive associations between all test species and concanavalin A control (with each other).

Data concerning bacterial adherence to test barrier materials at each time point are presented in Figures 2 through 5 (time effect). Associations between membrane types and bacteria adherence are summarized in Table 2 . Adherence of $B$. melaninogenicus and $P$. gingivalis to collagen membranes significantly increased as exposure time increased $(P<0.05)$. With increased exposure time, the adherence of $A$. viscosus, $B$. melaninogenicus, $P$. gingivalis, $P$. intermedia, and $S$. sanguis to ePTFE membranes also significantly increased $(P<0.05)$. In addition, $A$. viscosus, $S$. mutans, $S$. sanguis, and $T$. denticola showed significantly increased adherence to PLA membranes over time. Overall, as the exposure time increased, all test species with the exception of $A$. actinomycetemcomitans were associated with significantly increased adherence.

\section{DISCUSSION}

The purpose of this study was to determine the potential for a panel of orally-occurring bacteria to colonize $3 \mathrm{com}$ mercially available GTR barrier materials. The supragingival "model" presented here does not reproduce the complex environmental conditions which influence barriers placed surgically beneath gingival tissues. This subgingival environment is complex and presents a multitude of physical, immunologic, nutrient, and other conditions which are unique from the supragingival milieu. Our objective in using this model was to minimize these "subgingival" variables and to determine the pattern of bacterial colonization of barriers which are totally exposed within the oral cavity and thus largely unaffected by subgingival conditions or forces. As such, the information presented here may be considered intermediate between data derived from studies where barrier colonization was

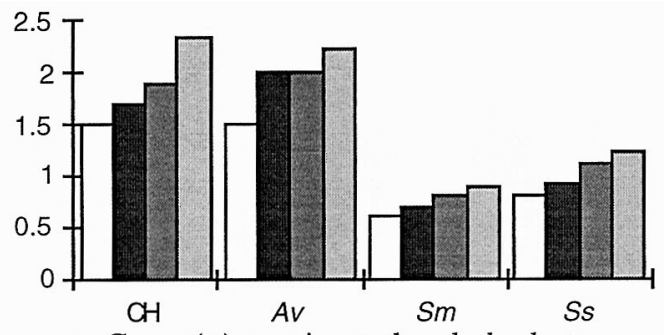

a. Gram (+) species and carbohydrate

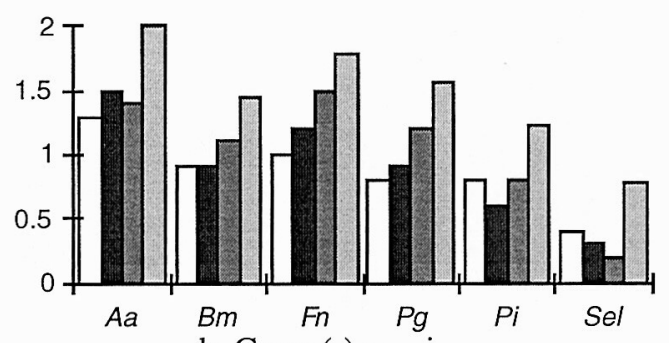

b. Gram (-) species

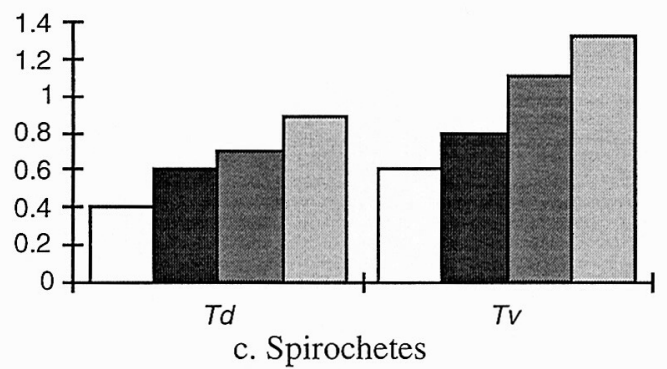
1 day
3 days
7 days
14 days

Figure 2. Bacterial adherence to tooth surface (control sites).

studied using in vitro methods or analyzed following retrieval of barriers used in traditional clinical situations.

A relatively high proportion of GTR barriers become exposed to the oral environment following subgingival surgical placement. ${ }^{8,20}$ Previous reports indicate that $70 \%$ of GTR treated cases may experience membrane exposure $^{8.20}$ with subsequent bacterial colonization of exposed membrane surfaces. Results of the present study suggest that both bioabsorbable and nonabsorbable materials will become colonized by a variety of bacterial types when totally exposed to the supragingival environment. Gramnegative bacterial species (i.e., $S$. mutans and $S$. sanguis), and Gram-positive species (i.e., A. actinomycetemcomitans, $B$. melaninogenicus, $F$. nucleatum, $P$. intermedia, $P$. gingivalis, $T$. denticola, and $T$. vincentii) associated with periodontal diseases were found to adhere to all 3 test GTR materials. These findings are in agreement with a previous report by Mombelli et al. wherein putative periodontal pathogens were cultured from retrieved GTR barriers $^{10}$; in that study, Gram-negative, anaerobic rods were 


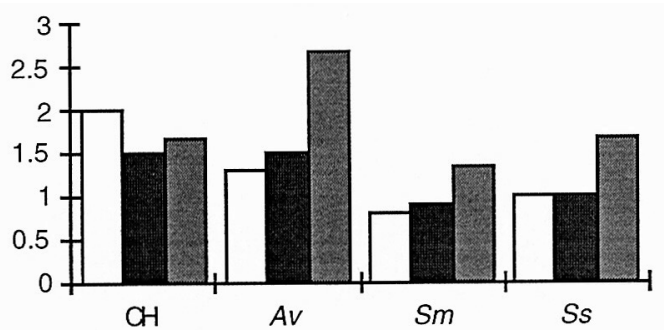

a. Gram (+) species and carbohydrate
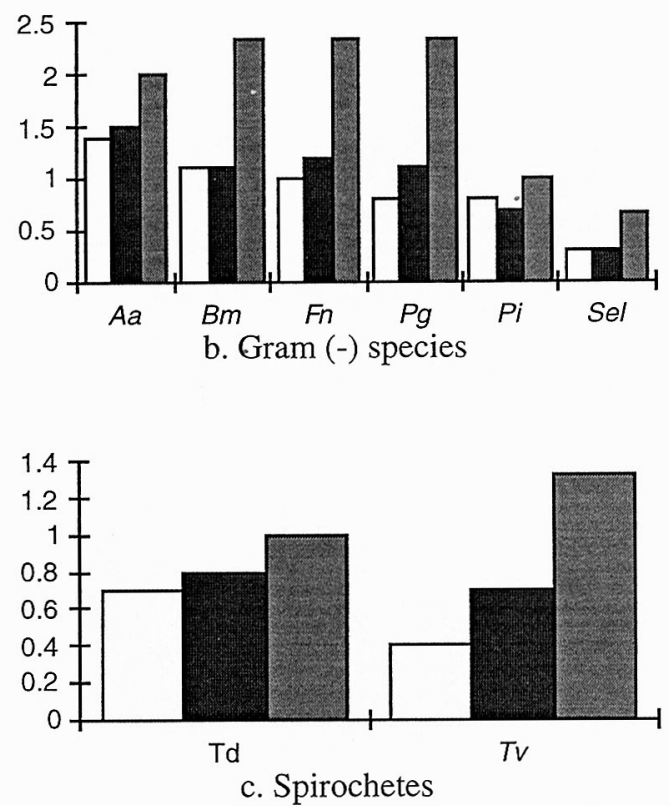

1 day

3 days

7 days

Figure 3. Bacterial adherence to collagen membranes.

found in all samples comprising $31 \%$ of all organisms cultivated.

Results presented here also suggest that certain bacterial types may preferentially colonize GTR membranes. $A$. actinomycetemcomitans and $A$. viscosus were the predominant colonizing species detected on test materials while other species; e.g., S. sputigena, were detected less frequently. These findings are consistent with a previous study conducted by our group in which bacterial adherence to GTR membranes was determined using in vitro methods. ${ }^{2}$ In that study, we reported that $A$. actinomycetemcomitans and $A$. viscosus were among the 6 most strongly adherent microbial species, whereas $S$. sputigena had the lowest adherence capability. In contrast, Guillemin et al., ${ }^{20}$ using scanning electron microscopy (SEM), failed to find any clear pattern of microbial colonization on ePTFE barriers retrieved from subgingival therapeutic sites. These differences in research findings may be attributable to the varying methodologies used in individual studies examining membrane colonization. For example,

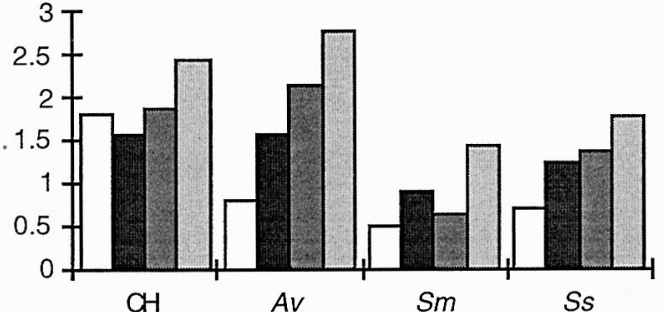

a. Gram (+) species and carbohydrate
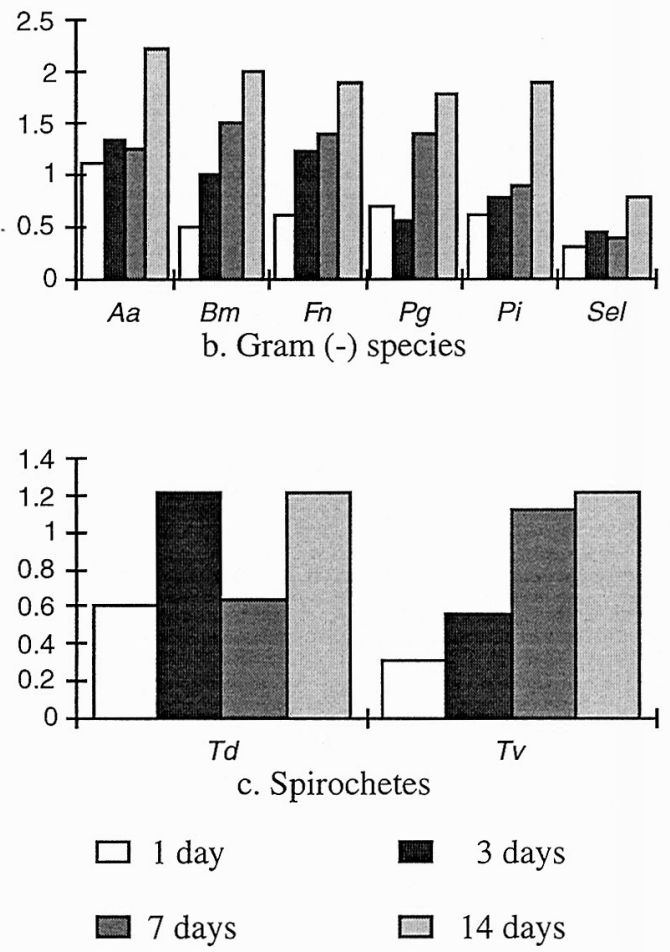

Figure 4. Bacterial adherence to ePTFE membranes.

results may differ widely depending upon whether in vitro or in vivo experimental conditions are employed or simulated; barriers are placed subgingivally or supragingivally; barriers are exposed to oral conditions for varying time periods; and whether microbial analysis/quantitation is conducted using culture, DNA probes, or microscopic techniques. The slot-immunoblot used in this study provides a reliable yet only semi-quantitative analysis of 11 selected microbial species. Furthermore, these results must be considered relative to the model used here in which membrane colonization may occur independent of subgingival immunologic defense mechanisms.

The extent to which bacterial colonization of GTR materials compromises successful therapy remains ill-defined, but evidence is emerging that microbial colonization is an unwanted sequela following membrane placement. The presence of bacterial plaque on retrieved GTR barriers has been associated with suboptimal clinical outcomes. ${ }^{6.11 .21 .22}$ Selvig et al. reported an inverse correlation 


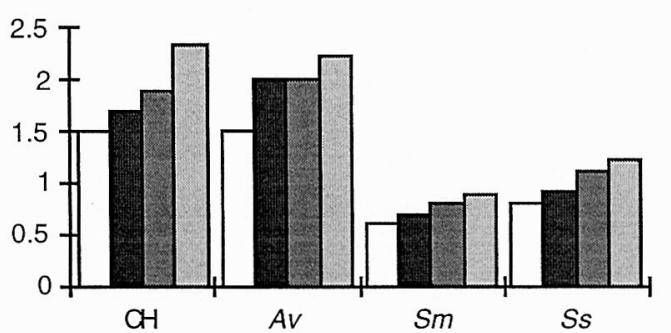

a. Gram (+) species and carbohydrate
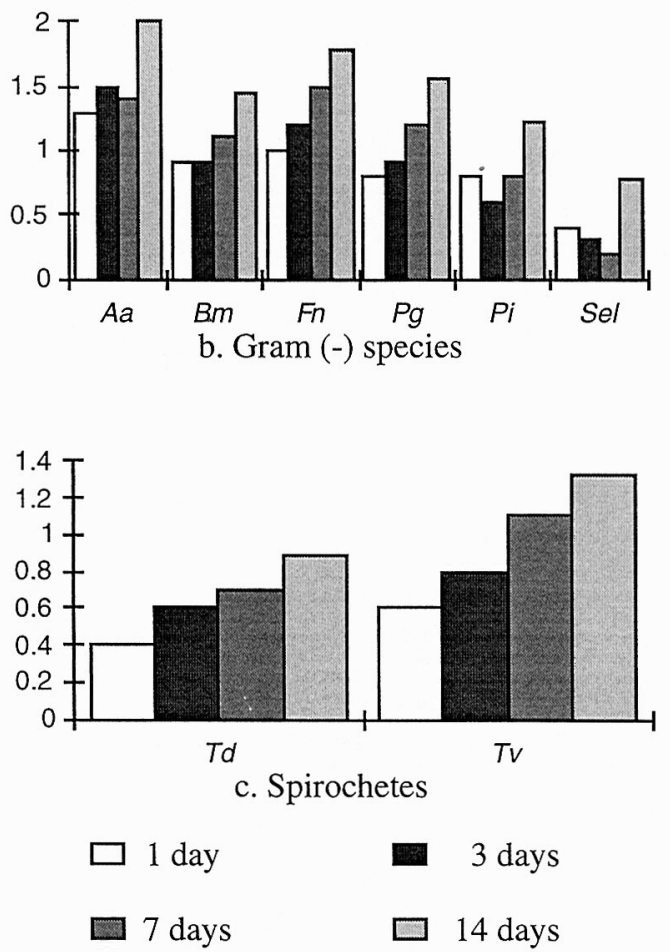

Figure 5. Bacterial adherence to polylactic acid (PLA) membranes.

between the extent of membrane contamination and gain in clinical probing attachment levels. ${ }^{6}$ Nowzari et al. ${ }^{11}$ demonstrated that sites where retrieved membranes had higher levels of recovered microorganisms $\left(>10^{8}\right)$ exhibited loss or only small gains in attachment, whereas sites with membranes harboring fewer microorganisms $\left(<10^{8}\right)$ had a gain in probing attachment. Specific bacterial types/ species have also been suggested to be detrimental to regenerative tissue formation. For example, membranes with high levels of black-pigmented anaerobic rods have been associated with sites exhibiting attachment loss ${ }^{11}$ while $A a$ negative sites have been correlated with attachment gain. ${ }^{21}$ Results from the present study indicate that $A a$ has a strong affinity for the 3 common GTR membranes tested here. The frequency by which $A a$ was detected in this study may reflect upon the relatively young age of the study participants (average age $=31$ ) where $A a$ may be more prevalent versus older groups; ${ }^{23}$ whether $A a$ would have a similar potential to affect partially submerged membranes in older patients remains to be determined.

The frequent identification of $A$. viscosus in orally-exposed barriers raises the question whether root surfaces unsuccesfully treated by GTR barrier therapy (i.e., absence of new tissue attachment) may be at increased risk for root caries subsequent to this treatment. A. viscosus is a normal component of the oral flora and may play an etiological role in the pathogenesis of human root surface caries. $^{24}$ If $A$. viscosus preferentially adheres to and colonizes GTR materials, it is possible that these materials may provide a portal of entry for this microbe to the gingival crevice/pocket and root surface. Conversely, it is also possible that upon removal or degradation of GTR materials, the subgingival environment converts back to its original microbial profile. Obviously, further studies are required to determine if species exhibiting increased barrier adherence persist or proliferate subgingivally following barrier removal.

Participants in the present study refrained from conventional oral hygiene procedures during the study period and did not receive systemic antibiotics or antimicrobial mouthrinses. These directives obviously depart from the postsurgical regimen which typically follows surgical GTR barrier placement. However, this protocol allows a rather unique determination of the ability of oral bacteria to colonize GTR materials independent of mechanical or chemical plaque control. In addition, the benefits of using systemic antibiotics subsequent to GTR therapy have not been clearly demonstrated. Demolon et al., using paper point specimen collection and DNA probe bacterial detection, have reported that the total bacterial load at test sites over time increased similarly for patients with or without post-therapy antibiotics, ${ }^{25}$ it was concluded that

Table 2. Time Effect of Membrane Types on Bacterial Adherence

\begin{tabular}{|c|c|c|c|c|c|c|c|c|c|c|c|c|}
\hline Membrane & $\mathrm{CH}$ & $\mathrm{Aa}$ & Av & $\mathrm{Bm}$ & Fn & $\mathrm{Pg}$ & $\mathrm{Pi}$ & $\mathrm{Sm}$ & Ss & Sel & $T d$ & $\mathrm{TV}$ \\
\hline Control & & & & & & & & & & & & 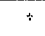 \\
\hline Collagen & & & $*$ & 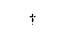 & & $*$ & & & & & & \\
\hline ePTFE & & & $\theta$ & 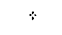 & * & : & + & $*$ & $i$ & & & $*$ \\
\hline PLA & & & $\uparrow$ & & & - & & 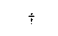 & $\dagger$ & & $i$ & \\
\hline All membranes & & & $\hat{\imath}$ & $\dagger$ & $*$ & $\dagger$ & $\div$ & + & 4 & + & $\dot{\gamma}$ & $t$ \\
\hline
\end{tabular}

*Marginally significant $(P=0.06)$ from baseline.

Statistically significantly different from baseline $(P<0.05)$. 
once a membrane is placed, the amount of attached bacteria in barrier treated sites increases over time independent of use of adjunctive antibiotics. ${ }^{25,26}$ Under the conditions of this present study, bacterial adherence also increased with time (i.e., up to 14 days for the adherence to control sites, ePTFE, and PLA membranes; up to 7 days for control sites and all test membranes). A similar pattern of bacterial adherence has been reported in vitro. ${ }^{12}$ Therefore, it appears that a clinical dilemma exists in GTR therapy; i.e., bacterial colonization of exposed membranes can be anticipated, yet antimicrobial therapy may have marginal effects on this process. ${ }^{25.26}$ These findings emphasize the need to achieve initial and sustained tissue coverage over GTR membrane sites.

Our results indicate that bioabsorbable (e.g., collagenous) barriers possess a potential similar to nonabsorbable membranes for microbial colonization. An important issue to consider is whether premature oral exposure of absorbable barriers, especially those composed of collagen, may hasten membrane degradation and compromise regenerative tissue formation. For example, colonization of collagen-based barriers by bacterial types which produce proteolytic enzymes may accelerate membrane dissolution and prematurely reduce the occlusive properties of these particular materials. ${ }^{22}$ Wang et al., studying bacterial adherence to and degradation of membranes in vitro, have reported that $P$. gingivalis possesses relatively high collagenolytic activity versus other tested species. ${ }^{12}$ As suggested by Mayrand and Grenier, ${ }^{27}$ collagenolytic activity could be either the result of combined activities of a specific collagenase ( $P$. gingivalis) and/or nonspecific proteases ( $B$. melaninogenicus, $A$. actinomycetemcomitans, $F$. nucleatum, etc.). In addition, the process of collagen degradation could be enhanced intraorally by salivary enzymes, mechanical trauma, and/or by collagenase known to be secreted by epithelial cells. ${ }^{28}$ While these degradative forces do exist subgingivally, it is reasonable to expect that the collective action of bacterial and hostderived degradative enzymes increases as membranes gain exposure to the oral environment. As a large proportion of membranes become exposed over time $e^{8.10 .20}$ and bacterial adherence increases with exposure time (as demonstrated here), bacterial degradation of absorbable membranes likely represents a significant clinical problem in GTR therapy.

Limitations of this study included the inability to quantify specific bacterial species. Slot immunoblot assay is a versatile, rapid, sensitive, reproducible, permanent, and relatively inexpensive technique to detect specific bacteria. ${ }^{18}$ As shown in this study, the relative quantity of each microbial species was determined by visual scoring; however, no definitive comparison can be made among species using these scoring criteria and more stringent investigations are required to verify the composition of each adherent plaque sample. Another limitation of this study is the possibility of false-positive reactions due to crossreactivity of antibodies; however, the antibodies used in this study are known to have very limited cross-reactivity to other antigens (unpublished data). ${ }^{1.29 .30}$

In summary, all test bacteria used in this study adhere to GTR membranes in the oral environment. Adherence increases as membrane exposure time increases. No differences in bacterial adherence, whether considering total numbers or species types, were noted among the three barrier types. It therefore appears that sustained gingival coverage of barrier materials should be a primary treatment objective during GTR therapy.

\section{REFERENCES}

1. Becker W, Becker BE. Treatment of mandibular 3-wall intrabony defects by flap debridement and expanded polytetrafluoroethylene barrier membranes. Long-term evaluation of 32 treated patients. $J$ Periodontol 1993;64:1138-1144.

2. Flores de Jacoby L, Zimmermann A, Tsalikis L. Experiences with guided tissue regeneration in the treatment of advanced periodontal disease. A clinical re-entry study. Part I. Vertical, horizontal and combined vertical and horizontal periodontal defects. J Clin Periodontol 1994;21:113-117.

3. Gottlow J, Nyman S, Karring T. Maintenance of new attachment gained through guided tissue regeneration. $J$ Clin Periodontol 1992;19:315-317.

4. Rominger JW, Triplett RG. The use of guided tissue regeneration to improve implant osseointegration. J Oral Maxillofac Surg 1994;52: 106-112.

5. Buser D, Bragger U, Lang NP, Nyman S. Regeneration and enlargement of jaw bone using guided tissue regeneration. Clin Oral Implants Res 1990;1:22-32.

6. Selvig KA, Kersten BG, Chamberlain AD, Wikesjö UM, Nilveus RE. Regenerative surgery of intrabony periodontal defects using ePTFE barrier membranes: Scanning electron microscopic evaluation of retrieved membranes versus clinical healing. $J$ Periodontol 1992;63:974-978.

7. Lu HK. Topographical characteristics of root trunk length related to guided tissue regeneration. J Periodontol 1992;63:215-219.

8. Selvig KA, Nilveus RE, Fitzmorris L, Kersten B, Khorsandi SS. Scanning electron microscopic observations of cell populations and bacterial contamination of membranes used for guided periodontal tissue regeneration in humans. J Periodontol 1990;61:515-520.

9. Warrer K, Karring T. Guided tissue regeneration combined with osseous grafting in suprabony periodontal lesions. An experimental study in the dog. J Clin Periodontol 1992;19:373-380.

10. Mombelli A, Lang NP, Nyman S. Isolation of periodontal species after guided tissue regeneration. J Periodontol 1993;64:1171-1175.

11. Nowzari H, Slots J. Microorganisms in polytetrafluoroethylene barrier membranes for guided tissue regeneration. $J$ Clin Periodontol 1994;21:203-210.

12. Wang HL, Yuan K, Burgett F, Shyr Y, Syed S. Adherence of oral microorganisms to guided tissue membranes: An in vitro study. $J$ Periodontol 1994;65:211-218.

13. Carlsson J. Presence of various types of non-haemolytic streptococci in dental plaque and in other sites of the oral cavity in man. Odontol Revy 1967;18:55-74.

14. Vincent JW, Suzuki JB, Falkler W Jr, Cornett WC. Reaction of human sera from juvenile periodontitis, rapidly progressive periodontitis, and adult periodontitis patients with selected periodontopathogens. J Periodontol 1985;56:464-469.

15. Saglie FR, Simon K, Merrill J, Koeffler HP. Lipopolysaccharide from Actinobacillus actinomycetemcomitans stimulates macrophages 
to produce interleukin-1 and tumor necrosis factor mRNA and protein. Oral Microbiol Immunol 1990;5:256-262.

16. Irving JT, Socransky SS, Heeley JD. Histological changes in experimental periodontal disease in gnotobiotic rats and conventional hamsters. $J$ Periodont Res 1974;9:73-80.

17. Newman MG. The role of Bacteroides melaninogenicus and other anaerobes in periodontal infections. Rev Infect Dis 1979;1:313-324.

18. Van Poperin N, Lopatin DE. Slot immunoblot assay for detection and quantitation of periodontal disease-associated microorganisms in dental plaque. J Clin Microbiol 1991;29:2554-2558.

19. Johnson DA, Gautsch JW, Elder JH. Improved technique utilizing nonfat dried milk for analysis of proteins and nucleic acids transferred to nitrocellulose. Gene Anal Tech 1984;1:3-8.

20. Guillemin MR, Mellonig JT, Brunsvold MA. Healing in periodontal defects treated by decalcified freeze-dried bone allografts in combination with ePTFE membranes (I). Clinical and scanning electron microscope analysis. J Clin Periodontol 1993;20:528-536.

21. Machtei EE, Cho MI, Dunford R, Norderyd J, Zambon JJ, Genco RJ. Clinical, microbiological, and histological factors which influence the success of regenerative periodontal therapy. $J$ Periodontol 1994;65:154-161.

22. Pitaru S, Tal H, Soldinger M, Noff M. Collagen membranes prevent apical migration of epithelium and support new connective tissue attachment during periodontal wound healing in dogs. J Periodont Res 1989;24:247-253.
23. Slots J, Reynolds HS, Genco RJ. Actinobacillus actinomycetemcomitans in human periodontal disease: a cross-sectional microbiological investigation. Infect Immun 1980;29:1013-1020.

24. Syed SA, Loesche WJ, Pape HLJ, Grenier E. Predominant cultivable flora isolated from human root surface caries plaque. Infect Immun 1975; 11:727-731.

25. Demolon IA, Persson GR, Moncla BJ, Johnson RH, Ammons WF Effects of antibiotic treatment on clinical conditions and bacterial growth with guided tissue regeneration. $J$ Periodontol 1993;64:609_ 616.

26. Demolon IA, Persson GR, Ammons WF, Johnson RH. Effects of antibiotic treatment on clinical conditions with guided tissue regeneration: One-year results. J Periodontol 1994;65:713-717.

27. Mayrand D, Grenier D. Detection of collagenase activity in oral bacteria. Can J Microbiol 1985;31:134-138.

28. DeCarlo A, Windsor LJ, Wells B, Caufield PW, Taylor RE, BirkedalHansen H. Collagenolytic activity of mucosal keratinocytes: inductive role of $B$. gingivalis. J Dent Res 1988; 67 (Spec. Issue): 210(Abstr. 779).

29. Newman MG. The role of infection and anti-infection treatment in regenerative therapy. J Periodontol 1993;64:1166-1170.

Send reprint requests to: Dr. Hom-Lay Wang, University of Michigan, School of Dentistry, 1011 N. University Ave., Ann Arbor, MI 481091078.

Accepted for publication July 9, 1996. 